\title{
Pressão de vapor e evaporação
}

\author{
Vapor Pressure and Evaporation
}

Luciana Dornelles Venquiaruto (venquiaruto@uri.com.br)

Universidade Regional Integrada do Alto Uruguai e das Missões (URI) - Campus Erechim

Marcos Rogério Dallago (dallago@uricer.edu.br)

Universidade Regional Integrada do Alto Uruguai e das Missões (URI) - Campus Erechim

Lucas Oliveira Schnorrenberger (quimicalucas@gmail.com)

Universidade Regional Integrada do Alto Uruguai e das Missões (URI) - Campus Santo Ângelo, PPG Ensino Científico e Tecnológico

Resumo: Com o intuito de viabilizar ações que contribuam com um ensino de ciências mais contextualizado, foi desenvolvido o presente trabalho de pesquisa, o qual buscou correlacionar, por intermédio da experimentação, os conceitos de pressão de vapor e evaporação, com situações do cotidiano de alunos e professores, tornando desta forma o ensino de química mais significativo. A pesquisa se caracteriza por ser experimental. Foram desenvolvidos experimentos, a temperatura ambiente, com diversos solventes, armazenados em placas petry de tamanhos diferentes e submetidas a distintas ações externas (sem e com fluxo forçado de ar). O tempo de evaporação total dos solventes apresentou tendência inversa com a pressão de vapor dos mesmos para todas as situações avaliadas. Pode-se observar também que, independente do solvente, os ensaios conduzidos com a placa petry com maior área superficial e submetidos a um fluxo forçado de ar apresentaram menores tempos para a completa evaporação dos solventes, explicando assim questões do nosso cotidiano, como o porquê de a roupa secar mais rápido em dias ventosos.

Palavras-chave: Evaporação; Pressão de Vapor; Química.

Abstract: The present research work was developed to the aim to enable actions that contribute to a more contextualized science teaching, which correlates, through experimentation, the concepts of vapor pressure and evaporation, with everyday situations of students and teachers, thus making the chemistry teaching more meaningful. The research was carried out experimentally. Also, the experiments were performed at environment temperature, using several solvents, stored in Petri Dishes of different sizes and submitted to different external actions (without and with forced air flow). The total evaporation time of the solvents presented an inverse tendency with the vapor pressure for all evaluated situations. We can also observed that independent of the solvent, the tests conducted with the Petri Dish of the larger surface area and exposed to a forced airflow exhibited shorter times for the complete evaporation of the solvents, thus explaining our daily questions, such as why clothes dry faster on windy days.

Key words: Evaporation; Vapor Pressure; Chemistry.

\section{INTRODUÇÃO}


Você já se perguntou por que a água de uma poça d'água evapora? Porque alimentos desidratados ao sol secam mais rapidamente em dias ensolarados e com vento? Porque os cabelos secam mais rápido com o auxílio de um secador? Porque a acetona evapora se o frasco ficar aberto?

A resposta a estas perguntas estão relacionadas a dois conceitos: evaporação e pressão de vapor. O conceito de evaporação é, normalmente, conhecido pelos alunos pelo fato de ser facilmente exemplificado, como uma das etapas do ciclo da água na natureza, sendo entendido como um processo físico, caracterizado pela passagem de moléculas da fase líquida para a fase gasosa. Após passarem de fase, algumas moléculas da fase vapor se chocam com as moléculas do ar e/ou do próprio vapor, retornando a fase líquida (condensação). Quando as moléculas condensam na mesma proporção que evaporam, o sistema encontra-se em equilíbrio dinâmico e, neste instante, a pressão exercida pela fase vapor sobre sua fase líquida representa a pressão de vapor deste líquido. Quanto maior for à fase vapor de um líquido no equilíbrio dinâmico, maior será a pressão de vapor deste líquido.

Conceitualmente a pressão de vapor de um líquido pode ser entendida como uma propriedade coligativa vinculada a suas propriedades moleculares e à temperatura. Quanto maiores forem às forças de atração entre as moléculas na fase líquida, maior a dificuldade para que as mesmas escapem para a fase vapor e, consequentemente, menor será a pressão de vapor deste líquido e sua volatilidade (ATKINS e JONES, 2013). Em relação a temperatura, sua elevação proporciona um aumento na energia cinética das moléculas, facilitando sua passagem, através da camada superficial, para a fase vapor, conduzindo a um aumento na pressão de vapor do líquido (RUSSELL, 2013).

Para líquidos sempre iremos observar pressões de vapor inferiores a pressão atmosférica, que atua como uma barreira a ser superada, forçando as moléculas da fase gasosa a retornarem para a fase líquida. Quando a pressão de vapor de um líquido atinge a pressão atmosférica, mediante o fornecimento de energia (aquecimento), esta barreira imposta pela pressão atmosférica deixa de existir e as moléculas da fase líquida automaticamente passam para a fase vapor. A temperatura na qual a pressão de vapor de um líquido se iguala à pressão atmosférica (1 atm ao nível do mar) é denominada de temperatura de ebulição. Por exemplo, a $100{ }^{\circ} \mathrm{C}$ (temperatura de ebulição da água) a 
água tem pressão de vapor igual a 1 atm. Quanto maior a pressão de vapor de um líquido, mais facilmente ele evaporará e, consequentemente, menor será sua temperatura de ebulição (ATKINS e PAULA, 2013).

Apesar de importante para entender alguns processos evaporativos, como os destacados no início deste texto, o tema pressão de vapor ainda é pouco discutido, hoje, nas escolas brasileiras de Ensino Médio, por exigir conhecimentos mais aprofundados de química, o que torna mais difícil sua compreensão.

Contribui para isso a carência de textos e experimentos adequados às necessidades de tais escolas. Para minimizar a complexidade deste assunto apresentamos uma atividade experimental que visa desencadear discussões importantes com os alunos sobre o conceito de pressão de vapor e evaporação bem como a aplicação desses conceitos em nosso dia a dia.

\section{MATERIAIS e REAGENTES}

Os materiais e reagentes utilizados para o desenvolvimento da atividade experimental estão descritos na Tabela 1. Para as Escolas que não dispõem de reagentes e vidrarias específicos para laboratórios, sugerimos para alguns reagentes substituintes que poderão ser adquiridos no comércio local.

Tabela 1. Materiais e reagentes usados em laboratório e seus possíveis substituintes

\begin{tabular}{l|ll}
\hline Materiais e reagentes de laboratório & Materiais convencionais \\
\hline Placas petry de $38,5 \mathrm{~cm}^{2} \mathrm{e} 78,5 \mathrm{~cm}^{2}$ & $\begin{array}{l}\text { Pires de xícaras de cafezinho e pires de } \\
\text { xícaras de chás }\end{array}$ \\
\hline Pipeta volumétrica de $10 \mathrm{~mL}$ & Seringa descartável \\
\hline Capela & ---- \\
\hline Ventilador & Ventilador & \\
\hline Acetona P.A. (propanona) & Acetona vendida em farmácias & \\
\hline Álcool etílico $99,3 \%$ & Álcool etílico 92,8 \% e/ou Álcool \\
& combustível \\
\hline Diclorometano & Cloreto de metileno \\
\hline Clorofórmio & ---- & \\
\hline
\end{tabular}

Fonte: autoria própria 
Vale ressaltar que a acetona comercial vendida em farmácias apresenta geralmente apenas $50 \%$ de propanona. Devido ao fato desse solvente ser utilizado para o refino de drogas ilícitas, as autoridades competentes proibiu a venda a pessoas físicas do produto puro. Já o cloreto de metileno utilizado em indústrias que fazem espumas é vendido somente com licença da polícia federal, pois pode ser também empregado na síntese de entorpecentes. Esse ponto pode conduzir discussões acerca de temas diversos, tais como droga lícita e ilícita, a relação toxicidade e concentração de solventes, diferenças entre reagentes de laboratório e produtos comerciais, entre outros.

Salienta-se que o uso do produto comercial não gera problemas para o resultado do experimento em sala de aula.

\subsection{Procedimento}

A correlação existente entre a pressão de vapor e a evaporação foi avaliada experimentalmente mediante o acompanhamento do tempo despendido para a evaporação total de seis solventes: água, etanol, acetona P.A., acetona comercial, clorofórmio e diclorometano. Os solventes utilizados no experimento se caracterizam por apresentarem pressões de vapor diferentes (Tabela 2).

Considerando que diferentes fatores possam afetar a evaporação, foram conduzidos ensaios variando a área superficial da fase líquida, na ausência e na presença de fluxo forçado de ar, avaliando o tempo necessário para a evaporação total. Estes ensaios foram conduzidos empregando placas petry com áreas superficiais de $38,5 \mathrm{~cm}^{2}$ (pequena) e 78,5 $\mathrm{cm}^{2}$ (grande). Cada um dos seis solventes foi avaliado em três condições distintas (repouso na bancada, em frente a um ventilador e em uma capela de exaustão), nos dois tamanhos diferentes de placas petry, totalizando 36 ensaios.

A cada placa petry foram adicionados $10 \mathrm{~mL}$ de solvente com o auxílio de uma pipeta volumétrica. Posteriormente, um conjunto de cada solvente, à temperatura ambiente, foi submetido a uma ação externa distinta em relação ao fluxo de ar. Dos três conjuntos referentes a cada solvente, um não foi exposto a um fluxo forçado de ar, permanecendo apenas em repouso sobre uma bancada no laboratório (Figura 1a). Os dois conjuntos restantes foram expostos à presença de distintos fluxos forçados de ar, 
gerados mediante o uso de uma capela (Figura 1b) e de um ventilador (Figura 1c). Todos os ensaios tiveram seu tempo cronometrado em relação à evaporação total.



(a)

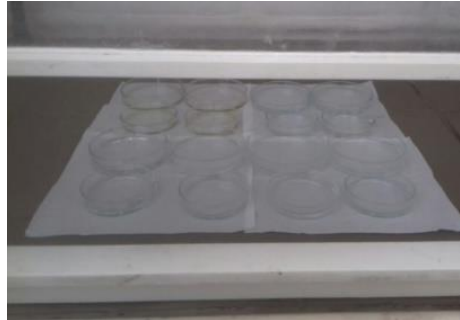

(b)

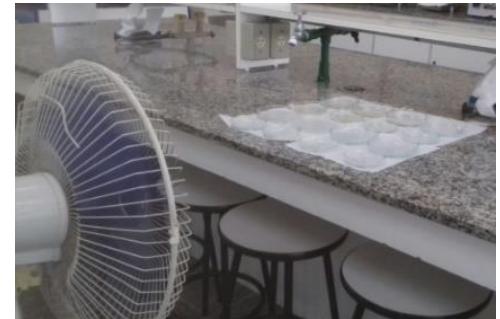

(c)

Figura 1- Condições ambientais a que foram expostas as placas petry contendo os diferentes solventes: a) bancada sem fluxo forçado de ar, b) capela e c) ventilador.

Reforça-se que o experimento poderá ser ajustado as condições de cada Escola.

\section{RESULTADOS E DISCUSSÕES}

A Tabela 2 apresenta alguns parâmetros de cada solvente utilizado, bem como os tempos necessários para a completa evaporação dos $10 \mathrm{~mL}$ dos solventes nas placas petry submetidas às 3 condições experimentais avaliadas neste estudo.

Tabela 2- Tempos de evaporação total e pressão de vapor

\begin{tabular}{|c|c|c|c|c|c|c|c|c|}
\hline \multirow{3}{*}{ Solvente } & \multirow{3}{*}{$\begin{array}{l}\text { Ponto de } \\
\text { Ebulição } \\
\text { (K) }\end{array}$} & \multirow{3}{*}{$\begin{array}{l}\text { Pressão de } \\
\text { Vapor }\end{array}$} & \multicolumn{6}{|c|}{ Tempo para evaporação total a $20^{\circ} \mathrm{C}$ (minutos) } \\
\hline & & & \multicolumn{2}{|c|}{ Em capela } & \multicolumn{2}{|c|}{ Com Ventilador } & \multicolumn{2}{|c|}{$\begin{array}{l}\text { Condições } \\
\text { ambientes }\end{array}$} \\
\hline & & & $\begin{array}{l}\text { Petry } \\
\text { (p) }\end{array}$ & $\begin{array}{l}\text { Petry } \\
(G)\end{array}$ & $\begin{array}{l}\text { Petry } \\
\text { (p) }\end{array}$ & $\begin{array}{l}\text { Petry } \\
(\mathrm{G})\end{array}$ & $\begin{array}{l}\text { Petry } \\
\text { (p) }\end{array}$ & $\begin{array}{l}\text { Petry } \\
(G)\end{array}$ \\
\hline $\begin{array}{l}\text { Água } \\
\mathrm{H}_{2} \mathrm{O}\end{array}$ & 373,1 & $\begin{array}{c}23 \mathrm{hPa} \\
20^{\circ} \mathrm{C}\end{array}$ & 289 & 275 & 407 & 315 & 4422 & 4047 \\
\hline $\begin{array}{c}\text { Álcool etílico } 92,8 \% \\
\mathrm{C}_{2} \mathrm{H}_{6} \mathrm{O}\end{array}$ & 351,4 & $\begin{array}{c}50 \mathrm{hPa}^{*} \\
20^{\circ} \mathrm{C}\end{array}$ & 147 & 105 & 175 & 169 & 398 & 346 \\
\hline $\begin{array}{l}\text { Diclorometano P.A. } \\
\qquad \mathrm{CH}_{2} \mathrm{Cl}_{2}\end{array}$ & 312,9 & $\begin{array}{c}470 \mathrm{hPa}^{* *} \\
20^{\circ} \mathrm{C}\end{array}$ & 3,57 & 2,42 & 8 & 6 & 51 & 41 \\
\hline $\begin{array}{c}\text { Clorofórmio P.A. } \\
\mathrm{CHCl}_{3}\end{array}$ & 334,0 & $\begin{array}{c}213 \mathrm{hPa} * * \\
20^{\circ} \mathrm{C}\end{array}$ & 15,9 & 13,15 & 28 & 13 & 103 & 71 \\
\hline $\begin{array}{l}\text { Acetona P.A. } \\
\mathrm{C}_{3} \mathrm{H}_{6} \mathrm{O}\end{array}$ & 329,3 & $\begin{array}{c}246 \mathrm{hPa}^{* *} \\
20^{\circ} \mathrm{C}\end{array}$ & 13 & 11 & 36 & 12 & 105 & 89 \\
\hline Acetona comercial & - & - & 30 & 19 & 28 & 18 & 256 & 157 \\
\hline
\end{tabular}

hPa: hectopascal (100 Pa); P.A.: Para análise

*Fonte: CRUZ et al., 2003. 
Pode-se observar que, independente do solvente, os ensaios conduzidos com a placa petry com área superficial maior $(G)$ e submetidos a um fluxo forçado de ar, apresentaram menores tempos para a completa evaporação dos solventes.

Outra tendência observada foi à relação inversa entre o tempo de evaporação com a pressão de vapor dos solventes, com os solventes com maior pressão de vapor (diclorometano, acetona e clorofórmio), apresentando os menores tempos de evaporação.

A pressão de vapor de um líquido é uma propriedade coligativa vinculada a suas propriedades moleculares e à temperatura (ATKINS e PAULA, 2013). Sendo assim, e considerando que não houve variação de temperatura entre os ensaios, a tendência observada para o tempo de evaporação (água > etanol > acetona comercial > clorofórmio > acetona > diclorometano) demonstra nitidamente a influência das propriedades moleculares sobre a pressão de vapor e a volatilidade dos líquidos.

A água e o etanol, cujas estruturas moleculares estão representadas na Figura 2a e 2b, caracterizam-se por serem moléculas capazes de formar ligações intermoleculares fortes, mediante ligações de hidrogênio (Figura 3), dificultando assim o escape das moléculas da fase líquida para a fase vapor. Coerente com esta propriedade, foram os solventes que apresentaram os maiores tempos para a evaporação total. Cabe ressaltar que os mesmos apresentam as menores pressões de vapor dentre os solventes estudados (Tabela 2).<smiles>CCO</smiles>

(a) Água (b) Álcool etílico<smiles>ClCCl</smiles>

(c)<smiles>ClC(Cl)Cl</smiles>

(d)<smiles>CC(C)=O</smiles>

(e) Diclorometano Clorofórmio Acetona

Figura 2- Fórmulas estruturais de alguns dos solventes avaliados neste estudo 


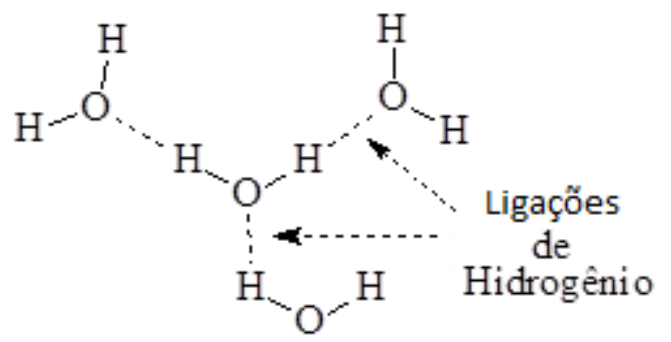

(a)

Interações intermoleculares entre moléculas de água

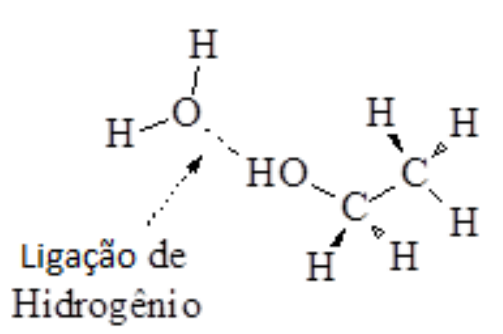

(b) de água e etanol

Figura 3 - Representação de ligações intermoleculares mediante ligações de hidrogênio ocorrendo entre (a) moléculas de água e (b) molécula de água e etanol.

A ligação de hidrogênio, também chamada de ponte de hidrogênio (Figura 3) consiste em uma interação intermolecular forte entre moléculas que contêm átomos de hidrogênio ligados a átomos de elevada eletronegatividade. Nestas moléculas o átomo de hidrogênio forma uma "ligação intermolecular em ponte" entre átomos de elevada eletronegatividade de moléculas adjacentes (RUSSELL, 2013).

Neste contexto, os maiores tempos de evaporação observados para água, em relação ao etanol, foram vinculados a maior habilidade desta molécula em formar ligações de hidrogênio. A molécula de água apresenta dois (2) hidrogênios ligados a um átomo de oxigênio (altamente eletronegativo) capazes de formar ligações de hidrogênio (Figura 3a). O etanol por sua vez, apresenta somente um (1) hidrogênio (referente ao grupo $\mathrm{OH}$ ) capaz de formar este tipo de ligação intermolecular (Figura 3b). Os demais hidrogênios do etanol, por estarem ligados a átomos de carbono encontram-se impossibilitados de formar ligações de hidrogênio.

Para o diclorometano, clorofórmio e acetona, cujas fórmulas estruturais estão representadas nas Figuras $2 \mathrm{c}, 2 \mathrm{~d}$ e 2e, respectivamente, foram observados tempos de evaporação total próximos entre si (por exemplo, para placa petry $\mathrm{G}$ submetida à capela, o tempo variou entre 2 e 13 minutos), porém distintos aos observados para o álcool etílico e a água, cujos tempos foram de 105 e 275 min, respectivamente. 
Os menores tempos de evaporação total observados para o diclorometano, clorofórmio e acetona, em relação a água e ao etanol, estão vinculados as diferentes ligações intermoleculares observadas entre estes dois grupos de moléculas. Ao contrário da água e do etanol, que apresentam interações intermoleculares fortes, devido à presença de ligações de hidrogênio, o diclorometano, clorofórmio e acetona, apresentam interações intermoleculares fracas do tipo dipolo-dipolo e atrações de London (RUSSELL, 2013).

A influência dos tipos de ligações intermoleculares sobre a volatilidade e a pressão de vapor podem ser melhor visualizadas quando comparamos, teoricamente, o dimetil éter (Figura 4) e o etanol (Figura 2b), ambos com fórmula molecular $\mathrm{C}_{2} \mathrm{H}_{6} \mathrm{O}$.

$$
\mathrm{H}_{3} \mathrm{C}^{-}{ }^{-} \mathrm{CH}_{3}
$$

Figura 4- Fórmula estrutural do dimetil éter

A presença do mesmo número de elétrons nos dois compostos sugere interações de London semelhantes, e então pressões de vapor semelhantes. No entanto, não é isto que se observa. A molécula de etanol, diferentemente do éter que apresenta todos os seus átomos de hidrogênio ligados a átomos de carbono, apresenta um grupo - OH que lhe permite formar ligações de hidrogênio intermolecular, as quais não estão presentes no dimetil éter. Como resultado desta diferença, o etanol é um líquido a temperatura ambiente, enquanto o dimetil éter é um gás (ATKINS e JONES, 2013).

A diferença observada entre a acetona P.A. e a comercial foi vinculada ao teor de água na amostra comercial. A presença de água, cuja pressão de vapor é superior à da acetona P.A., na formulação da acetona comercial, proporciona um aumento no tempo de evaporação desta amostra em relação a acetona P.A., a qual não apresenta água em sua composição.

Outros fatores que poderão contribuir para a evaporação são as ações externas que favoreçam o escape de moléculas da fase líquida para a fase vapor. Neste sentido foram conduzidos experimentos, empregando diferentes áreas superficiais de líquido, na 
ausência e na presença de fluxo forçado de ar, os quais possam auxiliar na compreensão de situações comumente observadas em nosso cotidiano as quais vem acompanhadas de questionamentos como: Como as poças de água, resultante das chuvas, mesmo encontrando-se em leitos impermeáveis e não atingindo a temperatura de ebulição (100 ${ }^{\circ}$ C) secam? Porque uma roupa em um varal seca mais rápido em dias de vento forte?

Os resultados referentes a este experimento (Tabela 2) demonstram que, independente do líquido (solvente) avaliado, temos uma mesma tendência em relação aos tempos de evaporação total, os quais estão coerentes com suas pressões de vapor. Os ensaios conduzidos com as placas petry com menor área superficial (p) apresentaram tempos de evaporação total maiores que os observados para os ensaios conduzidos empregando as placas petry maiores $(\mathrm{G})$. Para os ensaios conduzidos na ausência e na presença de fluxo forçado de ar, os menores tempos de evaporação total foram observados para os ensaios conduzidos na presença de um fluxo de ar (ventilador ou capela).

Considerando que a evaporação é um processo físico caracterizado pela transferência de moléculas de uma fase líquida para uma fase vapor e, que a mesma acontece, prioritariamente, a partir da superfície onde as moléculas estão ligadas menos fortemente e podem escapar mais facilmente para a fase vapor, o aumento da área superficial de um líquido amplia a região disponível para a transferência de fases, favorecendo a evaporação (RUSSEL, 2013).

Cabe salientar que a evaporação é um processo reversível (como todo processo físico), que ocorre concomitantemente com a condensação (passagem de moléculas da fase vapor para a fase líquida), apresentando uma relação moléculas evaporadas: moléculas condensadas, inicialmente favorável para a fase vapor (mais moléculas evaporam em relação as que se condensam), que com o passar do tempo tende à estequiometria (1:1), ou seja, ao equilíbrio dinâmico (Figura 5). Nesta condição, a pressão que a fase vapor exerce sobre sua fase líquida corresponde à pressão de vapor deste líquido, a qual se mantém constante, a uma determinada temperatura, independente da quantidade de fase líquida presente. Sendo assim, até existir uma fase líquida, a concentração molecular da fase vapor manter-se-á inalterada (ATKINS, JONES, 2013). 


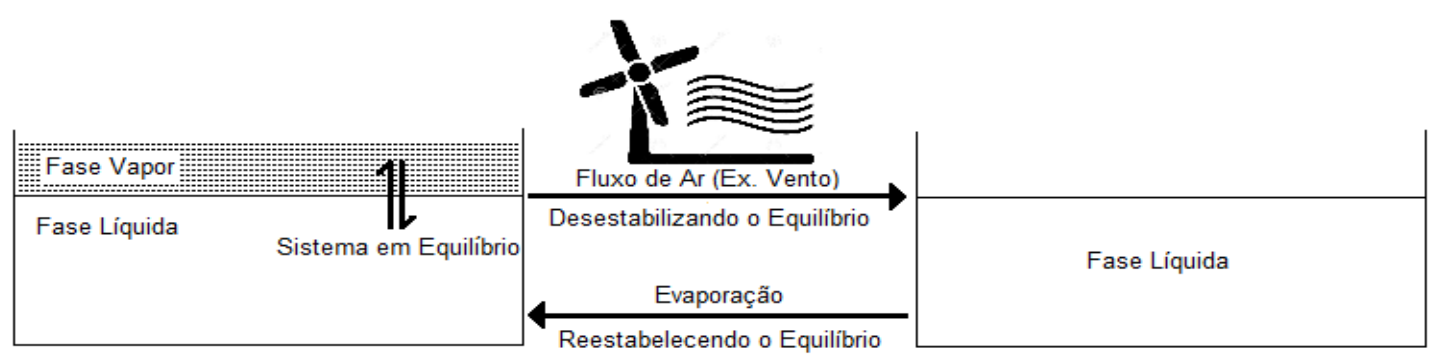

Figura 5- Sistema ilustrativo representando o conceito de pressão de vapor e sua relação com a evaporação.

Neste sentido, o fluxo de ar (vento) ao passar sobre o líquido desloca a fase vapor que estava em equilíbrio com a fase líquida. O sistema, a fim de reestabelecer o equilíbrio líquido-vapor, proporciona a transferência de moléculas da fase líquida para a fase vapor (Figura 5), as quais não retornam mais para a fase líquida, conduzindo assim a evaporação dos solventes, mesmo estes não tendo atingido suas temperaturas de ebulição, justificando assim os questionamentos inicias que nos levaram a investigar a temática que envolve evaporação e pressão de vapor.

\section{CONSIDERAÇÕES FINAIS}

O estudo visou o desenvolvimento de atividades experimentais referentes ao tema pressão de vapor e evaporação. O quadro teórico e os resultados do experimento permitiram a elaboração das seguintes considerações.

Uma conclusão teórica diz respeito ao conceito de pressão de vapor de uma substância, a qual resumidamente corresponde a pressão exercida pela fase vapor em equilíbrio com a fase líquido. Salienta-se que a pressão de vapor de um líquido aumenta com a temperatura, sendo ainda a mesma influenciada pelas forças intermoleculares.

Em relação aos resultados do experimento, os mesmos demonstram que a evaporação de líquido pode ocorrer mesmo em condições de temperatura inferiores à de ebulição, e que esta é diretamente influenciada pela área superficial do líquido e às condições externas a que o mesmo é submetido no processo de evaporação. 
O estudo demonstra que é possível, através da experimentação, correlacionar situações cotidianas de alunos e professores com conceitos químicos, tornando assim a educação por intermédio da química mais significativa.

\section{REFERÊNCIAS}

ATKINS, P. W; JONES, L. Princípios de química: questionando a vida moderna e o meio ambiente. Porto Alegre: Bookman, 2013.

ATKINS, P. W; PAULA, J. Físico-química. Rio de Janeiro: LTC, 2013.

CRUZ, M. J. F.; CARVAlHO, F. R.; STRAGEVITCH, L. Efeito de Aditivos Oxigenados na Pressão de Vapor de Gasolinas. In: 2 Congresso Brasileiro de Pesquisa \& Desenvolvimento em PETRÓLEO \& GÁS, 2003, Rio de Janeiro. 2 Congresso Brasileiro de Pesquisa \& Desenvolvimento em PETRÓLEO \& GÁS, v. único. p. 384, 2003.

PERUZZO, T. M.; CANTO, E. L. Química: na abordagem do cotidiano. 4. ed. São Paulo: Moderna, 2006.

RUSSEL, J. B. Química Geral. São Paulo: Makron Books, v.1. 2013.

SANTOS, W.L.P.; MÓL, G.S.; MATSUNAGA, R.T.; DIB, S.M.F.; CASTRO, E.N.F.; SILVA, G.S.; SANTOS, S.M.O.; FARIAS, S.B. Química e Sociedade. São Paulo: Editora Nova Geração, 2005. 